\title{
Bone Graft Substitutes in Maxillofacial Reconstruction - Structural and Biomechanical Perspectives
}

\author{
Shyam Sundar S. ${ }^{1}$, Sahith Kumar Shetty² \\ 1,2 Department of Oral and Maxillofacial Surgery, JSS Dental College and Hospital, \\ JSS Academy of Higher Education and Research, SS Nagar, Mysore, Karnataka, India.
}

\section{INTRODUCTION}

Reconstruction of a maxillofacial skeletal defect in the recent past has witnessed a paradigm shift in the process of treatment planning. It has now become a collaboration between the surgeon and the bioengineer to provide a customised stable reconstruction.

Understanding maxillofacial skeleton from an architectural and biomechanical perspective would not only guide the surgeon in planning a reconstruction but also the bioengineer to select the biomaterial and design an ideal reconstruction. This paper intended to provide an insight into scientific concepts which needed to be considered during the designing of biomaterials for reconstruction of maxillofacial skeletal defects.

Any object in the world, from a mechanical perspective is seen only as a material of varying physical and chemical (organic / inorganic) properties dwelling in a dynamic three-dimensional environment. Bone continuously has been re-modelling by adapting to the dynamic loading environment through an established force distribution pattern of equilibrium. ${ }^{1}$ Hence, for a patient requiring reconstruction of defects of varying dimensions within the craniomaxillofacial skeleton, its architectural complexity should be seen from both the surgeon's and bioengineer's perspective. Such multidisciplinary approach would provide a customized comprehensive reconstructive and rehabilitative solution. ${ }^{2}$

\section{BONE - BIOACTIVITY AND ARCHITECTURE}

Bone is a mixture of inorganic and organic material with cells of altering functions responsible for growth, repair and remodelling in a dynamic loading environment. ${ }^{3}$ Craniomaxillofacial skeletal architecture is a result of constant remodelling microscopically and macroscopically over a long time. ${ }^{4}$ Knowledge of these biological and biomechanical properties of bone should be used as a guide to choose the most appropriate biomaterial for customized reconstruction.

Differing from osteoinduction, osteostimulation is a process by which the implanted biomaterial microenvironment stimulates the growth factor recruitment, migration, and proliferation of cells for osteoinduction. ${ }^{5}$ It stimulates bone formation both at the centre of the scaffold and the edge of the graft, unlike osteoconduction where osteogenic cells migrate and proliferate within a scaffold and express their bioactivity. ${ }^{6}$

\author{
Corresponding Author: \\ Dr. Sahith Kumar Shetty, \\ FDSRCS, FFDRCS, \\ Associate Professor, \\ Department of Oral and Maxillofacial \\ Surgery, JSS Dental College and \\ Hospital, JSS Academy of Higher \\ Education and Research, SS Nagar, \\ Mysore, Karnataka, India. \\ E-mail: sahithkumarshetty @yahoo.co.in
}

DOI: $10.14260 /$ jemds/2021/486

How to Cite This Article:

Sundar SS, Shetty SK. Bone graft substitutes in maxillofacial reconstruction - structural and biomechanical perspectives. J. Evolution Med. Dent. Sci. 2021;10(31): 2369-2372, DOI:

10.14260/jemds/2021/486

Submission 08-03-2021,

Peer Review 26-05-2021,

Acceptance 02-06-2021,

Published 02-08-2021.

Copyright (c) 2021 Shyam Sundar S. et al. This is an open access article distributed under Creative Commons Attribution License [Attribution 4.0 International (CC BY 4.0)] 


\section{MICROSCOPIC TRABECULAR ARCHITECTURAL ENGINEERING}

Wolff's trajectorial theory proposes that trabecular architectural pattern decreases the bone stress and weight and the stress and strain are evenly distributed throughout the trabecular architecture. ${ }^{7}$

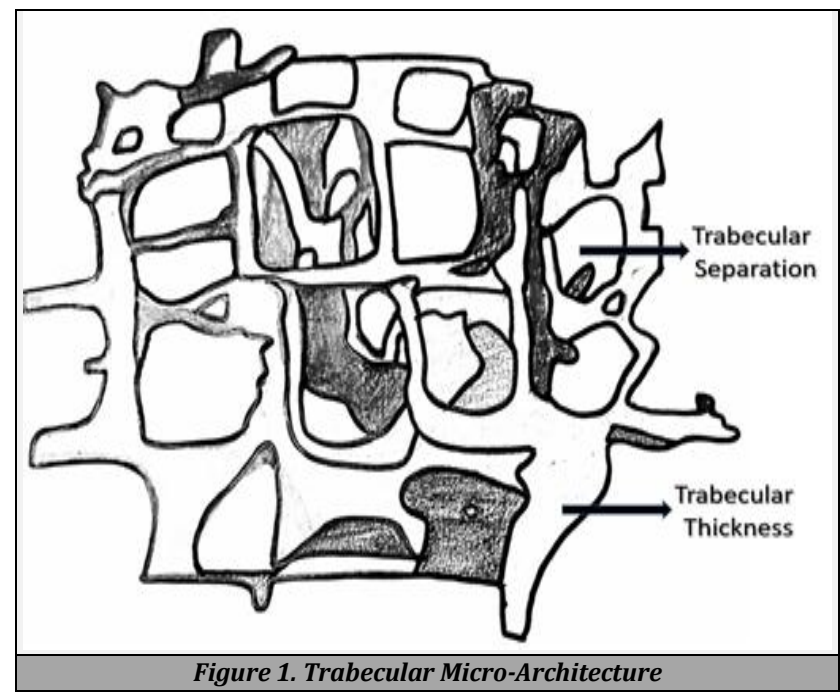

The key parameters of trabecular bone microarchitecture are the trabecular thickness, separation and number. (Fig 1) It gives broad understanding of crack propagation through the collagen matrix-Hydroxyapatite composite. ${ }^{8}$ The compressive modulus and hardness are also affected by the anisotropy of bone which is further due to the differences in collagen fibre orientation between lamellae. Science also explores and states that if the bone hardness is a direct measure of the mineral content, the elastic modulus is a direct measure of the interconnectivity of organic and inorganic matrices. ${ }^{9-11}$

\section{MACROSCOPIC BALANCED FORCE DISTRIBUTION PATTERN}

The load applied at any given point over the craniomaxillofacial skeleton is distributed throughout the craniomaxillofacial skeleton in a balanced force distribution pattern. The design of a maxillofacial skeleton with uncompromised skeletal and dental health is a customised resultant of this balanced stress distribution.12,13 (Fig. 2)

Science based on Wolff's concepts also indicate that compressive stress stimulates the formation of new bone and hence it is an important factor of bone healing during the postoperative phase. ${ }^{14}$ The elasticity of the muscles and tendons attached to the craniofacial skeleton deform the facial bone architecture with every minute load on the craniomaxillofacial skeleton. But beyond its elastic deformation limits during heavy impacts the bone fails (fractures).

Hence this concept of reconstitution of balanced load distribution forms the basis of functional anatomical reduction and internal fixation in the surgical treatment of facial bone repair or reconstruction. ${ }^{15}$

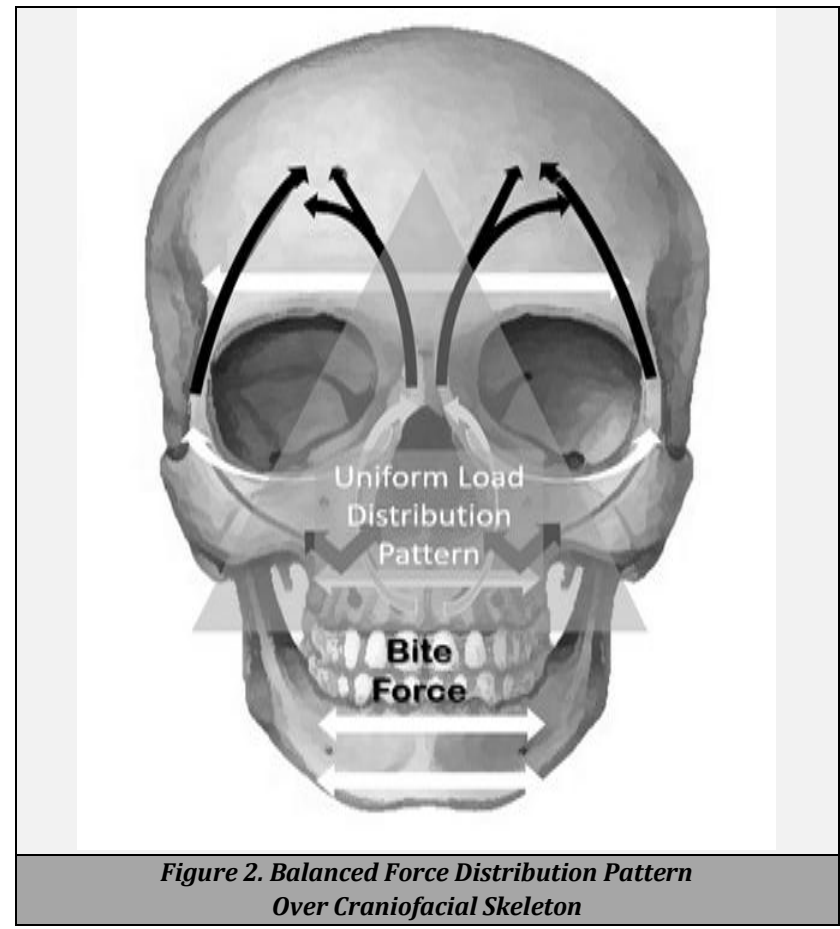

\section{BIOMECHANICAL SCAFFOLD DESIGN CONSIDERATIONS OF TRABECULAR MICROARCHITECTURE}

Finite element analysis of bone allows us to study bone biomechanics at macro, meso, micro and nano levels. ${ }^{16}$ At the macro level bone biomechanics is researched as a whole. A proper accurate description of boundary conditions is fundamental for a meaningful calculation of physiological tissue loading for whole bone. At a meso level, porous trabeculae are viewed with small rod like and plate like struts. At meso level, Finite Element Analysis (FEA) studies the trabecular architecture and mechanical properties from biomaterial research perspective. At a nano level, the FEA can be used to study the geometry of trabeculae and also factors which can be incorporated into the microarchitecture of scaffold biomaterial for bone bioactivity. ${ }^{17}$

The continuum level FEA is able to incorporate the material complexity like inhomogeneity, anisotropy, and nonlinearity. ${ }^{18}$ But accurate bone microstructure studies are not possible. Microstructural level FEA also called as Voxel FEA is able to calculate stress / strain behaviour locally within an individual trabecula, helping research at micro architectural level bone biomechanics. The prediction of mechanical behaviour increased when a greater number of architectural features were considered during FE analysis. Trabecular connectivity is a measure of number of struts meeting at a node. The trabeculae with less than 12 three-dimensional network connectivity displayed more bending on deformation and the ones with more than 12 network connectivity stretching dominated, indicating that the material is stiffer. ${ }^{19}$

The knowledge of bone at various levels is essential to customise a design of the scaffold three dimensionally, so that biomechanical failures can be avoided at micro as well as macrostructural levels. 


\section{STRUCTURAL IMPLICATIONS OF BIOMATERIAL POROSITY ON OSTEO-ACTIVITY}

Macro and micro porosity of a biomaterial are important for osteogenesis and angiogenesis. ${ }^{20}$ Macro porosities with an average pore size of more than $100 \mu \mathrm{m}$ encourage body fluid imbibition, cell migration to the core of the implant, angiogenesis and osteogenesis. Surface roughness, free energy, charge and chemical functionality affect the local microenvironmental osteogenic cell attraction and interaction. The roughness and free energy of the surface in particular are important for osteogenic protein adsorption. ${ }^{21,22}$ The micro porosities in the biomaterial provide more nucleation sites for apatite precipitation, by causing more degradation and release of calcium and phosphate. ${ }^{23}$ With time, the scaffold is resorbed completely and replaced by native bone.

The rate of degradation should be equal to rate of new bone formation. It has been shown that non microporous Hydroxyapatite scaffold is non osteoinductive whereas the microporous HA with a pore size of $0.4(\mu \mathrm{m})$ is osteogenic. It has shown 10 times more adsorption of albumin and fibronectin. ${ }^{24}$ Hence, the structural design of the biomaterial scaffold has marked influence on bioactivity.

The concavity incorporated scaffold, induces bone formation in the inner pores and concave surfaces and never on the convex surface. The osteoblasts have affinity preferentially to grooved surfaces of the scaffold architecture. ${ }^{25}$ The micro porosities not only enhance the surface area of biomaterial to enhance more osteogenic protein adsorption sites but also induce capillarity, so much that they anchor cells which affect osteogenesis, resize and absorb them into the micropore even if pore size is slightly smaller than the anchored cell.

It has also been reported that, even if the microporous scaffolds did not contain calcium and phosphate in their chemical structure, the calcium and phosphate ions present in the body fluids are absorbed into the micro porosities which further laydown the apatite within the scaffold. Few osteogenic proteins are also co-precipitated during the process which induce differentiation of the trapped cells into osteogenic lineage. ${ }^{26}$ Mechanotransduction controls proliferation and differentiation of bone cells because micromotions at interface of the scaffold-bone are very important for bioactivity of bone cells. ${ }^{27}$ The scaffold after implantation leads to early infiltration of immune cells followed by attraction of osteogenic cells and secretion of osteoid resulting in regeneration of functional organised native bone tissue. The scaffold then is degenerated due to immune cell infiltration and subsequent release of hydrolytic enzymes like lysosomal acid lipase, cholesterol esterase and reactive oxygen species. Decreased mechanical properties of the scaffold during its degradation will be compensated by the increased mechanical properties of the new bone formation inside the scaffold. ${ }^{28}$

\section{CONCLUSIONS}

The current scientific fraternity has taken up the challenge to achieve biomimicry by innovating biomaterials which mimic bone both structurally and functionally. Osteogenesis, osteoinduction, osteoconduction, osteostimulation and bone remodelling are the biologically active processes of bone which takes place either individually or simultaneously to keep up the physiologic equilibrium of bone tissue. Though it might or might not be possible to incorporate all ideal bioactivities in a single biomaterial, understanding these bioactivities and trabecular microstructural complexities would guide the scientific community to provide a conducive environment for all bioactivities to occur to achieve a stable and functional reconstruction of minor / major maxillofacial skeletal defects.

Financial or other competing interests: None.

Disclosure forms provided by the authors are available with the full text of this article at jemds.com.

\section{REFERENCES}

[1] Rudderman RH. Biomechanical considerations in facial fractures. Facial fracture surgery symposium, plastic surgery education symposium. Plastic 1987:23-5.

[2] Narra N, Valasek J, Hannula M, et al. Finite element analysis of customized reconstruction plates for mandibular continuity defect therapy. J Biomech 2014;47(1):264-8.

[3] Wu T, Yu S, Chen D, et al. Bionic design, materials and performance of bone tissue scaffolds. Materials (Basel) 2017;10(10):1187.

[4] Burr DB, Allen MR. Bone growth, modelling and remodelling. Basic and Applied Bone Biology. Chap. 5. 2nd edn. Academic Press 2019:85-100.

[5] Hu YC, Zhong JP. Osteostimulation of bioglass. Chin Med J (Engl) 2009;122(19):2386-9.

[6] Albrektsson T, Johansson C. Osteoinduction, osteoconduction and osseointegration. Eur Spine J 2001;10(Suppl 2):S96-101.

[7] Frost HM. Wolff's Law and bone's structural adaptations to mechanical usage: an overview for clinicians. Angle Orthod 1994;64(3):175-88.

[8] Voide R, Schneider P, Stauber M, et al. The importance of murine cortical bone microstructure for microcrack initiation and propagation. Bone 2011;49(6):1186-93.

[9] Ascenzi A. The micromechanics versus the macromechanics of cortical bone--a comprehensive presentation. J Biomech Eng 1988;110(4):357-63.

[10] Pilia M, Guda T, Pollot BE, et al. Local microarchitecture affects mechanical properties of deposited extracellular matrix for osteonal regeneration. Mater Sci Eng C Mater Biol Appl 2014;35:122-33.

[11] Fonseca H, Moreira-Goncalves D, Coriolano HJA, et al. Bone quality: the determinants of bone strength and fragility. Sports Med 2014;44(1):37-53.

[12] Pakdel AR, Whyne CM, Fialkov JA. Structural biomechanics of the craniomaxillofacial skeleton under 
maximal masticatory loading: Inferences and critical analysis based on a validated computational model. J Plast Reconstr Aesthet Surg 2017;70(6):842-50.

[13] Rudderman RH, Mullen RL, Phillips JH. Implications of finite analysis. In: Pollock RA, ed. Craniomaxillofacial buttresses: anatomy and operative repair. New York, NY: Thieme 2012:19-21.

[14] Takano-Yamamoto T. Osteocyte function under compressive mechanical force. Japanese Dental Science Review 2014;50(2):29-39.

[15] Rudderman RH, Mullen RL. Biomechanics of the facial skeleton. Clin Plast Surg 1992;19(1):11-29.

[16] Currey JD. The structure and mechanics of bone. Journal of Materials Science 2012;47(1):41-54.

[17] Schneider P, Stauber M, Voide R, et al. Ultrastructural properties in cortical bone vary greatly in two inbred strains of mice as assessed by synchrotron light based micro- and nano-CT. J Bone Miner Res 2007;22(10):155770.

[18] Taddei F, Schileo E, Helgason B, et al. The material mapping strategy influences the accuracy of CT-based finite element models of bones: an evaluation against experimental measurements. Med Eng Phys 2007;29(9):973-9.

[19] Liu XS, Sajda P, Saha PK, et al. Quantification of the roles of trabecular microarchitecture and trabecular type in determining the elastic modulus of human trabecular bone. J Bone Miner Res 2006;21(10):1608-17.

[20] Butscher A, Bohner M, Hofmann S, et al. Structural and material approaches to bone tissue engineering in powder-based three-dimensional printing. Acta Biomater 2011;7(3):907-20.
[21] Malmstrom J, Adolfsson E, Arvidsson A, et al. Bone response inside freeform fabricated macroporous hydroxyapatite scaffolds with and without an open microporosity. Clin Implant Dent Relat Res 2007;9(2):7988.

[22] Rouahi M, Gallet O, Champion E, et al. Influence of hydroxyapatite microstructure on human bone cell response. J Biomed Mater Res A 2006;78(2):222-35.

[23] Kaiser JP, Reinmann A, Bruinink A. The effect of topographic characteristics on cell migration velocity. Biomaterials 2006;27(30):5230-41.

[24] Ghayor C, Weber FE. Osteoconductive microarchitecture of bone substitutes for bone regeneration revisited. Front Physiol 2018;9:960.

[25] Zhu XD, Zhang HJ, Fan HS, et al. Effect of phase composition and microstructure of calcium phosphate ceramic particles on protein adsorption. Acta Biomater 2010;6(4):1536-41.

[26] Su EP, Justin DF, Pratt CR, et al. Effects of titanium nanotubes on the osseointegration, cell differentiation, mineralisation and antibacterial properties of orthopaedic implant surfaces. Bone Joint J 2018;100-B(1 Supple A):9-16.

[27] Tsai CC, Su PF, Huang YF, et al. Oct4 Directly regulate dnmt1 to maintain self-renewal and undifferentiated state in mesenchymal stem cells. Molecular Cell 2012;47(2):169-82.

[28] Liu Y, Li JP, Hunziker EB, et al. Incorporation of growth factors into medical devices via biomimetic coatings. Philos Trans A Math Phys Eng Sci 2006;364(1838):23348. 